\title{
Transfusion Reactions Encountered at The Children's Hospital and Insti- tute of Child Health, Lahore, Punjab - A Clinical Audit
}

\author{
Nazish Saqlain*, Sidra Hareem and Nisar Ahmed
}

Department of Haematology and Transfusion medicine, The Children's Hospital and Institute of Child Health, Lahore, Pakistan.

\begin{abstract}
Any adverse event that occurs during or after transfusion for which no other cause can be established is labeled as a transfusion reaction. Since the advancements in screening tests for infectious diseases, non-infectious transfusion reactions are on the rise. The aim of this study was to assess the frequency of transfusion reactions and to do an audit of reaction reporting. It was a retrospective study done from 1st December 2014 to 31st December 2015 at The Children's Hospital and Institute of Child Health, Lahore Punjab. The data was retrieved from blood bank records. 22 transfusion reactions were reported, out of which the most common reaction was febrile non haemolytic transfusion reaction. Only one haemolytic transfusion reaction was seen. Among the blood components, most reactions were seen with packed red blood cells. In $90 \%$ of cases completely filled reporting forms were received, in $86 \%$ of cases post reaction EDTA samples were received, and in only $50 \%$ cases urine samples were received in blood bank. Pyrexia was the most frequent symptom in recipients. Re-audit will be done next year. Guidelines need to be followed and updated.
\end{abstract}

Keywords: Audit, Children, Transfusion reaction.

doi.org/10.21089/njhs.22.0080

\section{INTRODUCTION}

The concept of blood transfusion started approximately 200 years ago, when the earliest attempts were made to transfuse animal blood to humans and in $19^{\text {th }}$ century first inter-human transfusion was done [1]. Since then, transfusion practices have evolved and millions of transfusions are done annually as a life saving measure. Despite of all the advancements in blood banking, transfusion process is never completely safe and can result in a spectrum of unfavorable results. Any untoward event that occurs during or after transfusion for which no other foreseeable explanation can be given is labeled as a transfusion reaction [2], which may be acute or delayed. Due to the improved scrutiny of blood donors and improvements in infectious disease testing, infection related reactions have moved down the list and non-infectious complications are the major concern for a modern blood banker [3].

Haemo-vigilance is a system of supervision of the entire transfusion process from selection of donor to the transfusion of recipient, whose primary aim is to identify the complications associated with transfusion along their causes and their prevention in future, so that quality and safety of entire process is improved [3]. The application of hemovigilance var-

*Address correspondence to this author at the Department of Haematology and Transfusion medicine, The Children's Hospital and Institute of Child Health, Lahore, Pakistan. Tel: 0321-4709386; E-mail:nazish68@yahoo.com ies internationally, ranging from a nationwide centralized system with compulsory report of each and every transfusion reaction in France to a more voluntary system between professionals at a national level. In Asia, Japan has implemented hemovigilance through Red Cross and in India via Indian Pharmacopoeia Commission [4-6]. Recently a National Blood Transfusion Program has been introduced in Pakistan but is struggling for an establishment of hospital transfusion committees and an overall comprehensive system for the country [7].

The goal to conduct the audit in our centre was to get an overview of the different types and frequency of transfusion reactions occurring locally and to see the trends of transfusion reactions being reported, so that steps can be taken accordingly to prevent similar episodes in future and to decrease the wastage of the blood in a setup where voluntary donation is not the main source of blood. The hospital transfusion committee policies were used for reporting a transfusion reaction and further workup was derived from the guidelines of British Committee for Standards in Haematology (BCSH) and the American Association of Blood Banks (AABB). The working guidelines are available as printed copies at the hospital blood bank.

\section{MATERIALS AND METHODS}

\section{Settings and Duration}

This cross-sectional study was conducted at the Blood bank of The Children's hospital and ICH, Lahore from $1^{\text {st }}$ Decem- 
ber 2015 to $31^{\text {st }}$ December 2015 . The hospital is a tertiary care institute catering a large burden of oncology patients from the entire province of Punjab, and the hospital blood bank is responsible for providing the entire blood needs of hospital.

\section{Collection of Blood Products}

The blood is collected from healthy donors meeting the WHO criteria. A detailed history is taken from every donor followed by physical examination. They include directed, replacement and voluntary donors. The history Performa is filled and informed consent is taken from each donor before starting the blood collection.

\section{Evaluation of Transfusion Reactions}

All cases of suspected transfusion reactions were evaluated. The data was retrieved from blood bank records and hard copies of transfusion reaction reports. All suspected cases of transfusion reactions were reported to transfusion medicine unit using a standard reporting form with special emphasis on pre and post transfusion vitals and were investigated following a standard investigation protocol. All the cases were checked for any form of clerical error on part of hospital staff. Patient's pre and post transfusion sample with donor's sample were rechecked for blood-grouping, cross-matching and Direct and Indirect Coombs Test. Post transfusion sample were also sent for full blood picture, urinary haemoglobin and serum bilirubin. Sample from blood bag and segment were sent for sterility tests. Chest X-Ray was carried out only in the suspected cases of Transfusion associated Lung Injury (TRALI).

\section{Statistical Analysis}

Data was analyzed by SPSS22, quantitative variables are presented as mean and standard deviation and qualitative variables as frequency and percentages.

\section{Ethical Consideration}

The clinical audits are exempted for approval from the ethical committee of the hospital.

\section{RESULTS}

Total number of transfusions done in different departments of the hospital in one-year period were 29,358 , out of which whole blood units transfused were 7710 and rest 21,648 were different components of transfusions which included Packed red blood cells(PRBC), Fresh frozen Plasma(FFP) and random donors' platelets concentrates. A total of 22 transfusion reactions were reported, which constituted $0.07 \%$ of all transfusions. Patients receiving the transfusions ranged from 8 months to 13 years with median age of 5.25 years and male to female recipient ratio was 1:0. 48 Out of total reactions, 9(40\%) were directed against PRBCs out of which 1 was with washed PRBCs, 7(31\%) against FFPs, 5(22\%) against whole blood and only $1(0.04 \%)$ against platelets.

Table 1. Frequency of different types of reactions with different components.

\begin{tabular}{|c|c|c|c|c|c|c|}
\hline $\begin{array}{c}\text { Type of } \\
\text { Reaction }\end{array}$ & $\begin{array}{l}\text { PR } \\
\text { BCs }\end{array}$ & $\begin{array}{l}\text { FF } \\
\text { Ps }\end{array}$ & $\begin{array}{l}\text { Plate- } \\
\text { lets }\end{array}$ & $\begin{array}{l}\text { Whole } \\
\text { Blood }\end{array}$ & $\begin{array}{l}\text { To- } \\
\text { tal }\end{array}$ & $\begin{array}{c}\text { Per- } \\
\text { centage }\end{array}$ \\
\hline $\begin{array}{l}\text { Febrile Non- } \\
\text { Hemolytic } \\
\text { Transfusion } \\
\text { Reaction }\end{array}$ & 03 & 01 & & 02 & 06 & $27.2 \%$ \\
\hline Urticarial & 01 & 01 & & 02 & 04 & $18.1 \%$ \\
\hline Anaphylactic & & & 01 & & 01 & $4.5 \%$ \\
\hline $\begin{array}{l}\text { Acute Hemo- } \\
\text { lytic }\end{array}$ & 01 & & & & 01 & $4.5 \%$ \\
\hline Non specific & 02 & 02 & & & 04 & $18.1 \%$ \\
\hline Clerical error & & 01 & & & 01 & $4.5 \%$ \\
\hline $\begin{array}{l}\text { Not deter- } \\
\text { mined* }\end{array}$ & 02 & 02 & & 01 & 05 & $22.7 \%$ \\
\hline TOTAL & 09 & 07 & 01 & 05 & 22 & \\
\hline Percentage & $40 \%$ & $\begin{array}{l}31 \\
\%\end{array}$ & $0.04 \%$ & $22 \%$ & & $100 \%$ \\
\hline
\end{tabular}

*Because post transfusion samples were not received

Majority (90\%) of the reporting forms were completely filled and $10 \%$ were only partially filled. Most of the reactions $(81 \%)$ were reported after 1 hour of the reactions. Blood bags with tubing and EDTA and serum samples were received in $19(86 \%)$ cases and urine samples were received in half of the cases $(50 \%)$.

Table 2. Audit of Samples and Reporting Forms.

\begin{tabular}{|c|c|c|c|c|c|c|c|}
\hline \multicolumn{2}{|c|}{$\begin{array}{c}\text { EDTA } \\
\text { Samples }\end{array}$} & \multicolumn{2}{c|}{$\begin{array}{c}\text { Urine } \\
\text { Samples }\end{array}$} & \multicolumn{2}{c|}{$\begin{array}{c}\text { Reporting } \\
\text { Forms }\end{array}$} & \multicolumn{2}{c|}{$\begin{array}{c}\text { Arrival of } \\
\text { Forms }\end{array}$} \\
\hline Sent & $86 \%$ & Sent & $50 \%$ & $\begin{array}{c}\text { Com- } \\
\text { pletely } \\
\text { filled }\end{array}$ & $90 \%$ & $\begin{array}{c}\text { With- } \\
\text { in 1 hr }\end{array}$ & $81 \%$ \\
\hline $\begin{array}{c}\text { Not } \\
\text { sent }\end{array}$ & $14 \%$ & $\begin{array}{c}\text { Not } \\
\text { sent }\end{array}$ & $50 \%$ & $\begin{array}{c}\text { Partially } \\
\text { filled }\end{array}$ & $10 \%$ & $\begin{array}{c}\text { After } \\
1 \mathrm{hr}\end{array}$ & $19 \%$ \\
\hline
\end{tabular}

Highest reactions were reported from surgery department followed by Haematology/Oncology department. Most common symptoms among recipients were rash, urticaria, anxiety, headache, nausea, vomiting and fever. FNHTR was the most common type of reaction seen $(27 \%)$. There was only one haemolytic transfusion reaction due to wrong labeling of blood group on blood bag. 
Table 3. Frequency of Various Symptoms and Distribution in Various Wards.

\begin{tabular}{|c|c|c|c|}
\hline \multicolumn{2}{|c|}{ Symptoms } & \multicolumn{2}{c|}{ Wards } \\
\hline Fever & $90.9 \%$ & Surgery & $27 \%$ \\
\hline Rash & $54.5 \%$ & Oncology & $18 \%$ \\
\hline Urticaria & $18.1 \%$ & ICU & $13 \%$ \\
\hline Headache & $68.1 \%$ & Medicine & $13 \%$ \\
\hline Nausea & $50 \%$ & Emergency & $13 \%$ \\
\hline Backache and/or chest pain & $13.6 \%$ & Others & $13 \%$ \\
\hline
\end{tabular}

\section{DISCUSSION}

The reason to conduct this study in our setup was to analyze the spectrum of transfusion reactions and also to access the efficiency of the reporting system in use so that further changes or enhancements can be made to improve the hemovigilance. We tried to achieve both the goals by processing the post-transfusion samples to determine various types of reactions and in addition we looked at the timing of reporting of reaction and frequency of samples received from wards to assess how seriously the clinicians and paramedical staff are while dealing with the transfusion.

We observed that the rate of transfusion reactions at our hospital was low $(0.07 \%)$ and is not comparable to the more developed countries of the world like Brazil, France and Netherlands where rate of ATR are 2.6, 2.8 and 2.9 per 1000 transfused products respectively [13]. But the results are very much similar to the studies carried out at The Agha Khan University, Karachi, Pakistan and in India which showed the incidence of $0.082 \%$. and $0.05 \%$ respectively [11]. It is because of the under reporting of reactions in our setup due to lack of education regarding the diagnosis of transfusion reaction and importance of its reporting which leads to reporting of only the very obvious reactions and second fear of legal consequences in case of medical negligence during transfusion on part of medical professionals. This is also evident from the lack of samples in 5 cases of transfusion reactions which accounted for a major portion (22\%) of reactions which went unclassified. Another factor that could have contributed to the low incidence of Acute Transfusion Reactions in our setup is the routine practice to administer intravenous steroids and antihistamines pre- transfusion, these medications could mask the symptoms of acute reaction.

The commonest reaction was Febrile Non-Hemolytic Transfusion Reaction (FNHTR) followed by allergic reactions. This was comparable to a study conducted in North India which reported FNHTR and allergic reactions being the most common of all types of adverse transfusion reactions [8].
Majority of our patients had minor symptoms like fever, rash and pruritus. These findings were similar to Musa et al study who reported the commonest symptoms being fever, rigors, rash or urticaria [9]. No case of Transfusion Related Acute Lung Injury (TRALI) was reported in our study, which would be due to a rarity of this serious transfusion reaction and most importantly due to the lack of female donors in our country. In all of the reported transfusion reactions in our study, all the blood donations were taken from males. Similarly, no volume overload reaction was reported. In our present study, males were more affected than females similar to the study by Kumar et al. [14]. However, Sidhu et al. in their study found that females are more affected than males [15]. No gender association can be established from this study.

A single $\mathrm{ABO}$ incompatibility case was due to the clerical error, upon investigation of the case it was found out that there was no technical error, labeling of blood group on the blood bag was wrongly done. Such cases can be controlled by increasing the check points in the blood bank working area. The blood bank staffs' efficiency is directly related to their working hours, job environment and availability of senior staff in the situation of difficult cases. These points have been taken into account and discussed with the hospital transfusion committee.

Our study showed that the red cell transfusions were most commonly followed by acute transfusion reactions, followed by the FFP and platelet concentrates with the rates of $40 \%$, $31 \%$ and $04 \%$ respectively. However, the association cannot be established as PRBCs were the most issued and transfused components. Our findings were consistent with another study which reported blood components that caused most of transfusion reactions were RBCs followed by FFPs and platelets (Grujic J, 2012) [10]. In another study Riti et al showed similar results with most reactions occurring with whole blood followed by packed cells, FFPs and platelets [12].

Here an important point that needs attention is the ongoing use of whole blood even in a tertiary care setting. Another issue that needs to be highlighted is the importance of transfusion notes, both pre and post transfusion and vigilant transfusion monitoring, blood should preferably be transfused at morning in the presence of senior staff so that any reaction can be handled efficiently.

There is an increasing role of Hospital Transfusion Committees (HTC) to bring all the stakeholders to the table including the patients and attendants for improving their education regarding transfusion reactions and increasing the trend of voluntary donation. Special emphasis to the training of nursing staff should be given for early recognition of reaction as these are people that are in immediate contact with patients. More importantly HTC should outline the role of haematologist and setup protocols for any transfusion related emergency that needs his/her attention and his/her consultation 
should be sought immediately. Regarding Hemovigilance, reporting of transfusion reactions is essential in maintaining the quality control in the blood bank. One drawback of the study was that it lacked the reporting of delayed transfusion reactions because most of the patients were discharged after transfusion and later present in outdoor patient department for transfusion related complaints.

Lessons learnt from this audit were invaluable for our blood bankImprovements were made both at the blood bank to increase the accuracy of testing and dispatching the blood and also at the clinical end where need of increased sensitivity to transfusion reaction reporting and importance of post transfusion testing was highlighted. But these are initial steps to a well-managed hemovigilance system, the need of hour is re- auditing with wider parameters and increased involvement of society as well consisting of both recipients and donors.

\section{CONCLUSION}

It is important that transfusion reactions should be monitored carefully as they mimic sign and symptoms of many other clinical conditions. Early recognition and management is important but prevention is preferable. Patient safety as well as legal and ethical issues demand a well-organized and well maintained hemovigilance system with standardized data collection tools and response elements.

\section{CONFLICT OF INTEREST}

Declared none.

\section{ACKNOWLEDGEMENT}

Declared none.

\section{REFERNCES}

[1] Schmidt PJ, Leacock AG. Forgotten transfusion history: John Leacock of Barbados. BMJ. 2002; 325(7378): 1485-7. DOI: $10.1136 / \mathrm{bmj} .325 .7378 .1485$

[2] Gupta M, Kumar R, Gupta S, Kaur A. Acute transfusion reactions encountered in patients at a tertiary care centre in Punjab. Natl. Med. J. India., 2015; 28(01): 8-11.
[3] Eder AF, Linda A. Non-infectious complications of blood transfusion. Arch. Pathol., Lab. Med., 2007; 131(5): 708-718.

[4] Bisht A, Singh S, Marwaha N. Hemovigilance program-India. Asian J. Transfus. Sci., 2013; 7(1):73-74. DOI: 10.4103/09736247.106744

[5] Haslina MN, Fakhri MA, Saw TH, Salamah AS. An audit on acute transfusion reaction in North Eastern Malaysia. Scholarly J. Med. 2012; 2(5): 60-62.

[6] Karim F, MoizB, Shamsuddin N, Naz S, Khurshid M. Root cause analysis of non-infectious transfusion complications. Transfus. Aphersis. Sci., 2014; 50(1): 111-77.

DOI: $10.1016 /$ j.transci.2013.10.004

[7] Kassi M, Afghan AK, Khanani MR, Khan IA, Ali SH. Safe blood transfusion practices in blood banks of Karachi, Pakistan. Transfus. Med., 2011; 21(1):57-62. DOI: 10.1111/j.1365-3148.2010.01042

[8] Bhattacharya P, Marwaha N, Dhawan HK, Roy P, Sharma RR. Transfusion-related adverse events at the tertiary care center in North India: An institutional hemovigilance effort. Asian J. Transfus. Sci., 2015; 5(2):164-70. DOI: 10.4103/0973-6247.83245.

[9] Waiswa M.K, Moses A, Seremba E, Ddungu H, Hume H.A. Acute transfusion reactions at a national referral hospital in Uganda: a prospective study. Transfusion. 2014; 54(11) 2804-10. DOI: $10.1111 /$ trf. 12684

[10] Grujic J, Gulan Z, Budakov Z. Importance of haemovigilance and reports on transfusion reaction in blood component therapy. Med. Pregl., 2012; 65(1-2): 50-3. DOI: 10.2298/mpns1202050g

[11] Khalid S, Usman M, Khurshid M. Acute transfusion reactions encountered in patients at a tertiary care center. J. Pak. Med. Assoc., 2010; 60(10):832-6.

[12] Sinha R.T.K, Rai P, Dey A. A study of transfusion related adverse events at a tertiary care center in central India: a retrospective evaluation. J. Med. Sci. Health., 2016; 2(3): 6-12.

[13] Carneiro-Proietti A. Hemovigilance: a system to improve the whole transfusion chain. Rev. Bras. Hematol. Hemoter., 2013; 35(3): 158159. DOI: $10.5581 / 1516-8484.20130045$

[14] Kumar P, Thapliyal R, Coshic P, Chatterjee K. Retrospective evaluation of adverse transfusion reactions following blood product transfusion from a tertiary care hospital: A preliminary step towards hemovigilance. Asian J. Transfus. Sci., 2013; 7(2): 109-15. DOI: 10.4103/0973-6247.115564

[15] Sidhu M, Meenia R, Yasmeen I, Akhtar N. A study of transfusion related adverse events at a tertiary care centre in North India: An initiative towards hemovigilance. Int. J. Adv .Med., 2015; 2(3): 206-10. DOI: 10.18203/2349-3933.ijam20150545 